\title{
Interfaces de escritas coletivas em rede: um estudo de caso do jogo Chromaroma
}

\author{
Collective writing interfaces in network: \\ a case study of the game Chromaroma
}

design de jogos,

No presente artigo apresenta-se o resultado de revisão teórica sobre sistemas

cidade digital, coletivos contemporâneos e pesquisa de visualização de dados urbanos gerados georreferenciamento, colaborativamente. O objetivo foi analisar o comportamento emergente da produção visualização de dados

Isabella von Mühlen Brandalise, Rogério Camara

game design,

digital city,

georeferencing, data visualization de informação e as potencialidades narrativas de uma escrita coletiva em rede. A pesquisa foi iniciada a partir dos conceitos de cultura RAM, emergência, relações subjetivas no espaço urbano, deriva e psicogeografia. Realizou-se ainda um estudo de caso do jogo digital e físico Chromaroma, considerado representativo para o trabalho proposto, uma vez que os jogadores ressignificam a cidade e seu tradicional sistema de transporte a partir da experiência das partidas.

This article presents the results of a theoretical study of contemporary collective systems and a research of urban data visualization generated collaboratively. The objetive was to analyse the emergent behavior of information production and narrative potentialities of collective writing in network. The research began with the concepts of RAM culture, emergence, subjective relations in the urban space, drift and psycogeography. A case study of the game Chromaroma was conducted. It is considered representative for the work, since players reframe the city and its traditional transport system through the game experience.

\section{Introdução}

O presente artigo resulta de pesquisa acerca da contemporaneidade e manifestações que envolvem sistemas colaborativos, seguida por estudo de caso relativo à interação entre os sujeitos e o espaço público a partir de dispositivos móveis e elementos digitais em trânsito. O objetivo foi analisar o comportamento emergente da produção de informação e as potencialidades narrativas de uma escrita coletiva em rede, assim como as mediações e interações com o espaço de lugar (rua, trabalho, praça). Parte-se do pensamento sistêmico e emergente, característicos do período contemporâneo. Neste período, a profissão do designer adquiriu novas atribuições e uma crescente valorização. 
A capacidade de resolver problemas de forma ampla e holística é um diferencial em uma época marcada por complexidade, desordem e incerteza. Nesse sentido, exploram-se sistemas com dinâmicas colaborativas, refletindo sobre o design no contexto atual.

Procurou-se compreender sistemas de agenciamentos urbanos com múltiplas vozes e desdobramentos complexos. A problematização teve como foco a inserção de dispositivos digitais e a sua interferência na apreensão do espaço urbano pelos indivíduos. Dessa forma, voltou-se a pesquisa para visualizações de dados gerados coletivamente principalmente acerca do espaço urbano, com resultados formando mapas dinâmicos e emergentes.

Como referencial teórico foram investigados princípios contemporâneos de urbanismo abordados pelos internacional situacionistas. O grupo propunha novas formas de desfrutar das cidades, buscando situações de descoberta, jogo e experimentação. A pesquisa também teve como base os conceitos de rizoma e emergência, que dizem respeito a comportamentos coletivos sem um controle direto e centralizado, organizados de baixo para cima.

O jogo Chromaroma, objeto de análise deste artigo, foi desenvolvido pela empresa britânica Mudlark. Tem como ponto principal o transporte público coletivo, mas gera uma série de desdobramentos em termos de mudanças de percursos e formas de interpretação do espaço pelas pessoas. A situação de jogo amplia a experiência e a interatividade, ressignificando a cidade como uma forma de tabuleiro. Acima de tudo, o jogo se mostrou um objeto em que os jogadores tanto podem capturar a cidade quanto podem ser capturados pelos seus agentes, funcionando como um mecanismo de controle.

\section{Justificativa}

A pesquisa foi iniciada com a revisão teórica dos conceitos de cultura RAM (BREA, 2007), emergência (JOHNSON, 2003), relações subjetivas no espaço urbano, deriva e psicogeografia (Internacional Situacionismo), seguida de levantamento e análise de mapas, infográficos e outros objetos gerados a partir da inserção coletiva de dados e com resultados gráficos. Por fim, selecionou-se o jogo Chromaroma como representativo para o estudo de caso. A partir da escolha, realizou-se uma pesquisa teórica acerca do conceito de jogo (HUIZINGA, 2010; SCHELL, 2011) e especificamente de jogo pervasivo (MONTOLA, STENROS \& WAERN, 2009).

Com este estudo objetivou-se compreender os agenciamentos urbanos influenciados pelos meios técnicos de inscrição, sua difusão, consumo e condições sociais. A escolha da interface analisada se deu na medida em que esta articula os conteúdos emitidos em fluxo contínuo, revela as estruturas de uma cidade, permite investigar a forma como as pessoas se inserem na paisagem urbana e planifica a textura social emergente nos respectivos lugares de ação. Não 
desconsiderando o que as localizações em rede significam para as instituições, comunidades e espaços, destacam-se nesta pesquisa as possibilidades que estes programas e sistemas abrem de inscrições individuais e coletivas.

\section{Escritas coletivas e o jogo Chromaroma}

José Luis Brea (2007) fala sobre uma nova manifestação cultural na contemporaneidade. Enquanto a cultura sempre teve como princípio o arquivamento e a conservação do passado, a nova cultura, denominada cultura RAM, é dinâmica, baseada em processamentos, redes e na sua capacidade de interconexão. Nesse contexto, surge uma nova forma de subjetivação, abrindo espaço para o indivíduo multitudinário e coletivo, que atua como destinatário e gestor das novas formas de cultura.

Tal comportamento se relaciona diretamente com os sistemas rizomáticos e emergentes do período contemporâneo, caracterizados pela organização coletiva de baixo para cima, múltiplas entradas e saídas, ausência de um controle centralizado e formação de padrões.

A cidade é um caso claro de sistema emergente, uma vez que é o resultado dos usos que as pessoas fazem dela. O período atual implica diferentes ocupações e apropriações do espaço público, com sobreposições de lugares e funções. Novas propostas de urbanismo já vinham sendo exploradas pelo Internacional Situacionismo, movimento europeu de crítica social, cultural e política, fundado em 1957. O grupo defendia que cada indivíduo deve construir as situações de sua vida cotidiana, explorando seu potencial, rompendo com a alienação reinante e obtendo prazer próprio. As práticas propostas pelos situacionistas eram a deriva, a psicogeografia e o desvio, que constituem perambulações ao acaso pela cidade e estimulam as reinterpretações do espaço com base na experiência vivida. Uma vez que as atividades e intervenções no espaço urbano resultam das críticas à vida cotidiana, a arquitetura e o urbanismo surgem como dimensões fundamentais para o movimento. Além disso, o elemento de jogo é muito presente nas atividades dos protagonistas do movimento. Afinal, não há distinção entre jogo e seriedade, arte e vida cotidiana.

A integração entre jogo e vida cotidiana, sem uma distinção clara de seus limites, constitui uma das características fundamentais de um jogo pervasivo, tal como é o Chromaroma. Trata-se de um jogo para a cidade de Londres que envolve as plataformas virtual e física. A base é mostrar ao jogador os seus movimentos e localização pelo transporte público da cidade (metrô, ônibus e bicicleta, na primeira versão), por meio do reconhecimento do seu Oyster card (cartão unificado de transporte, identificado ao passar por cada estação). O objetivo do jogo é capturar o máximo de estações possível da cidade. Uma das ideias é incentivar as pessoas a alterarem seus trajetos e utilizar o transporte de formas diferentes. Os jogadores são divididos em quatro equipes (vermelha, amarela, azul e verde) 
que, além de buscar dominar a cidade, têm missões especiais, como a coleta de itens em estações secretas. Apesar de a ação do jogo se dar fisicamente no espaço da cidade, a sua visualização é por meio do site oficial. Ao capturar uma estação, a sua referência no mapa digital recebe uma circunferência na cor do time. Conforme mais jogadores do time capturam a mesma estação, a circunferência aumenta proporcionalmente de tamanho, gerando feedback visual e recompensas na forma de pontos. Assim, o mapa se configura como um sistema emergente, em que o controle é indireto e, a partir de regras simples, são gerados resultados complexos.

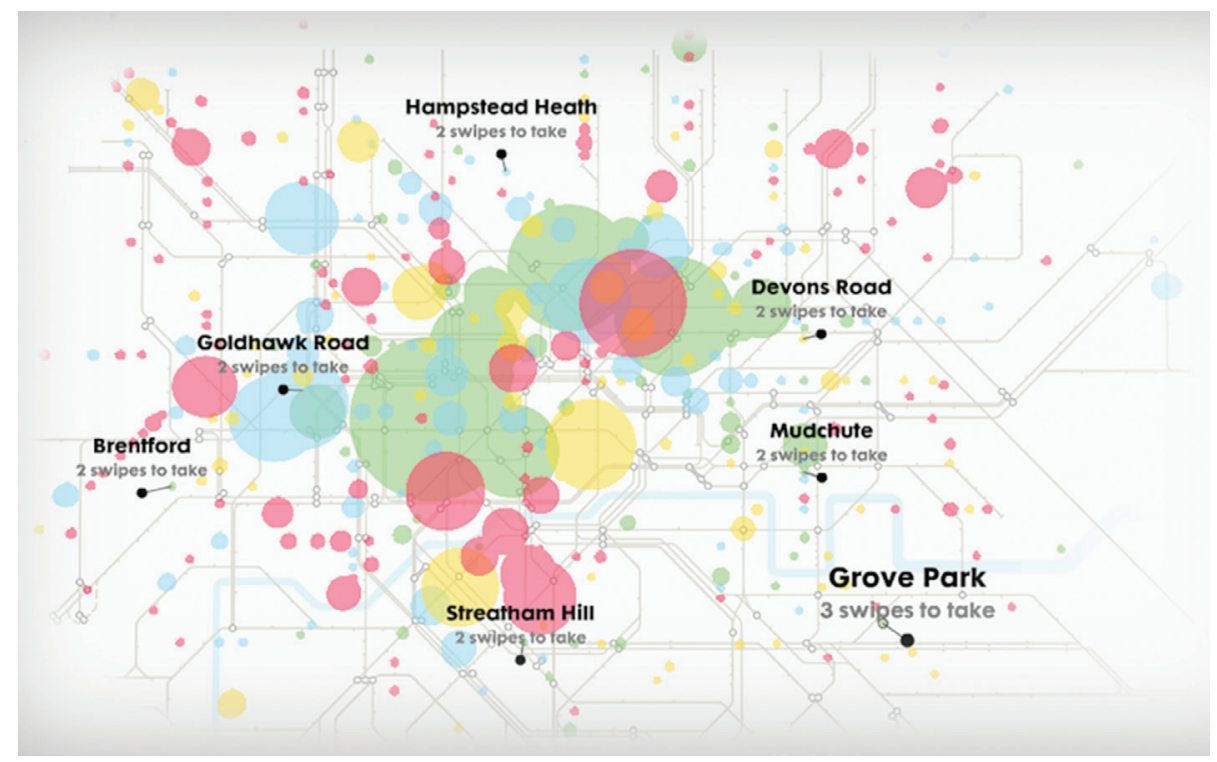

Figura 1 Mapa dinâmico do transporte público gerado a partir das atividades dos jogadores

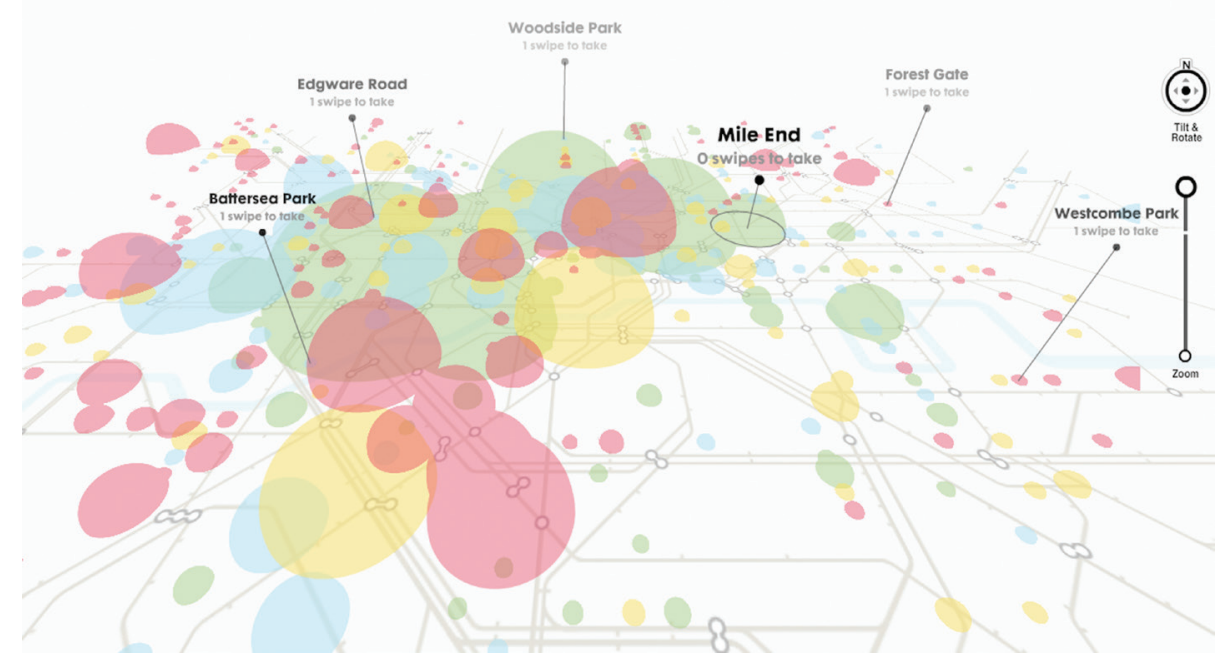

Figura 2 Visualização da ocupação de cada time no nível tridimensional 


\section{Considerações finais}

A análise de um caso real em que os jogadores registram seu percurso permitiu compreender de modo efetivo um sistema de visualização de dados, resultante de ações poéticas e escritas coletivas. A marcação das etapas de trajetória por cada jogador a partir da sua movimentação na cidade faz do jogo um sistema naturalmente contemporâneo de controle indireto e desdobramentos rizomáticos, além de reforçar as reflexões sobre a relação dos sujeitos com a cidade. Já que a cidade de cada um se dá a partir dos lugares que frequenta, a cidade passa a ser um conjunto dinâmico de cidades, com seus respectivos locais e relações afetivas. Gera-se uma experiência em que os jogadores vivem uma situação em que dominam a cidade enquanto, ao mesmo tempo, são controlados pelos mecanismos de registro. A proposta de alteração dos caminhos habituais pelo jogo incentiva não só uma liberação de determinadas vias de tráfego, mas também uma descoberta e ressignificação do espaço, assim como sugerem os internacional situacionistas. Por fim, no Chromaroma, a tecnologia e os recursos digitais desempenham um papel essencial como potencializadores e registradores das novas relações com o ambiente físico.

\section{Referências}

BREA, J. L. 2007. cultura_RAM. mutaciones de la cultura en la era de su distribución electrónica. Barcelona: Editorial GEDISA.

CHROMAROMA. In: <http://www.chromaroma.com/>, 20/10/2012.

DELEUZE, G. \& GUATTARI, F. 2000. Mil platôs: capitalismo e esquizofrenia. São Paulo: Ed. $34.1 \mathrm{~V}$.

HUIZINGA, J. 2010. Homo ludens: o jogo como elemento da cultura. São Paulo: Perspectiva. 6. ed.

JOHNSON, S. 2003. Emergência: a vida integrada de formigas, cérebros, cidades e softwares. Rio de Janeiro: Jorge Zahar Ed.

MCDONOUGH, T. 2002. Guy Debord and the Situationist International: Texts and documents. London: MIT press.

MONTOla, M.; STEnRos, J. \& WAERn, A. 2009. Pervasive Games: Theory and

Design. Elsevier.

SCHELL, J. 2011. A arte de game design: o livro original. Rio de Janeiro: Elsevier. 


\section{Sobre os autores}

Isabella von Mühlen Brandalise

<isabrandalise@gmail.com>

Estudante, UnB, Brasil

\section{Rogério Camara}

<rogeriojcamara@gmail.com>

Doutor, UnB, Brasil 